OPEN ACCESS

Edited by: Mats Bemark,

University of Gothenburg, Sweden

Reviewed by:

Johannes U. Mayer,

Victoria University of Wellington,

New Zealand

Reina Mebius,

VU University Medical Center,

Netherlands

*Correspondence:

Manuela Buettner

Buettner.Manuela@mh-hannover.de

${ }^{\dagger}$ Deceased

Specialty section:

This article was submitted to

Mucosal Immunity,

a section of the journal

Frontiers in Immunology

Received: 06 April 2020

Accepted: 21 December 2020

Published: 16 February 2021

Citation:

Basic M, Peppermüller PP, Bolsega S,

Bleich A, Bornemann M, Bode $U$ and

Buettner M (2021) Lymph Node Stromal Cells From Different Draining

Areas Distinctly Regulate the

Development of Chronic

Intestinal Inflammation.

Front. Immunol. 11:549473.

doi: 10.3389/fimmu.2020.549473

\section{Lymph Node Stromal Cells From Different Draining Areas Distinctly Regulate the Development of Chronic Intestinal Inflammation}

\author{
Marijana Basic ${ }^{1}$, Pia Pascale Peppermüller ${ }^{1}$, Silvia Bolsega ${ }^{1}$, André Bleich ${ }^{1}$, \\ Melanie Bornemann ${ }^{2}$, Ulrike Bode ${ }^{2 \dagger}$ and Manuela Buettner ${ }^{1,2 *}$ \\ 1 Institute for Laboratory Animal Science, Hannover Medical School, Hannover, Germany, ${ }^{2}$ Institute for Functional and \\ Applied Anatomy, Hannover Medical School, Hannover, Germany
}

The balance between the responsiveness of the intestinal immune system and the gut environment is fundamental for the maintenance of intestinal homeostasis, which is required for an adequate recognition of entering antigens. The disruption of this homeostasis by exaggerated immune response to harmless antigens can lead to the development of intestinal disorders such as inflammatory bowel disease. Stromal cells are sessile non-hematopoietic cells that build the backbone of the lymph node, an important site for the immune response induction, but also contribute to immune response and tolerance induction. However, the knowledge about the role of stromal cells in the regulation of inflammatory responses is still limited. Therefore, in this study we analyzed the influence of stromal cells on the development of chronic intestinal inflammation. Here, we show that intestinal inflammation alters the immune activation of the mesenteric lymph node-derived stromal cells. Podoplanin ${ }^{+}$and CD21/35 $5^{+}$stromal cells showed increased expression of MHC class II molecules, but CD106 expression on CD21/35+ cells was reduced. Stromal cells secreted cytokines and chemokines such as CCL7 and CXCL16 influenced the gut-homing phenotype and proliferation of $\mathrm{CD}^{+}$and $\mathrm{CD}^{+} \mathrm{T}$ cells. Furthermore, stromal cells of peripheral lymph nodes transplanted into the mesentery attenuated colitis severity in B6- $/ 110^{-/-}$mice. The reduced colitis severity in these mice was associated with increased expression of IL 4 and distinct activation pattern of stromal cells derived from transplanted peripheral lymph nodes. Altogether, our results demonstrate that lymph node stromal cells impact development of chronic colitis via T cell induction. Moreover, lymph node stromal cells from different draining area due to neonatally imprinted processes distinctly regulate the induction of immune responses.

Keywords: cytokines, stromal cells, lymph nodes, transplantation, chemokine 


\section{INTRODUCTION}

The mucosal surface of the gut is the first contact and recognition site for many antigens $(\mathrm{Ag})$. The intestinal homeostasis is required for an efficient decision whether entering Ag is harmless, such as food, or potentially pathogenic. To ensure the maintenance of the intestinal homeostasis, the host protective immunity and the gut microbiota have to be in balance. Disruption of this balance by exaggerated immune reaction to harmless antigens can lead to intestinal disorders such as inflammatory bowel disease (IBD). IBD is a chronic inflammatory disease of the gastrointestinal tract that encompasses Crohn's disease and ulcerative colitis. Interleukin 10 -deficient mouse model $\left(\mathrm{Il}_{10} \mathrm{O}^{-/-}\right)$is a genetically engineered model for IBD research (1). Histopathological hallmarks of colitis in $1 l 10^{-/-}$mice are inflammatory cell infiltration of the lamina propria and submucosa, epithelial hyperplasia, mucin depletion, crypt abscesses, ulceration, and thickening of the intestinal wall (2). Colitis development in mice carrying mutation in $\mathrm{Il10}$ gene starts shortly after weaning and is microbiota dependent, as germ-free mice do not develop any signs of inflammation $(3,4)$.

Lymph nodes (LN) are located at sites where pathogenic Ag might invade the host. They filter the lymph coming from the draining area and initiate immune responses. Every LN consists of mobile immune cells, e.g., dendritic cells (DCs) and lymphocytes, as well as sessile non-hematopoietic stromal cells (SCs) such as fibroblastic reticular cells (FRC) and follicular dendritic cells (FDC) $(5,6)$. Differences between the microenvironments of distinct $\mathrm{LN}$ are necessary to ensure an efficient immune response for the specific draining area of the LN. DCs and stromal cells of the mesenteric lymph nodes (mLN) preferentially express the retinal dehydrogenase 2 (RALDH2) (7-9). RALDH2 enzyme is involved in imprinting gut-homing specificity on $\mathrm{T}$ and $\mathrm{B}$ cells by upregulating the expression of guthoming receptor CCR9 $(10,11)$. Plasma cells in the mLN were found to predominantly produce IgA, whereas plasma cells induced in peripheral lymph nodes ( $\mathrm{pLN}$ ) were mainly IgG producing cells (12). Microarray-, RNAseq-, and protein analyses revealed various expression differences between stromal cells draining different areas, but also between distinct stromal cell subpopulations (13-17). All these variations result normally in an optimal immune response to protect the specific draining area of the LN. A lymph node transplantation model, in which peripheral lymph node fragments are transplanted into the mesentery, is a valuable tool to identify the influence of stromal cells on immune response and tolerance induction $(12,18,19)$. The transplanted lymph nodes (LNtx) regenerate within eight weeks to a fully functional $\mathrm{LN}$ repopulated with recipient-derived immune cells and donor-derived stromal cells $(7,18)$. Using this model, we were able to analyze the influence of stromal cells on chronic inflammatory diseases. In this study, mLN-derived cells from inflamed B6-Il10 ${ }^{-/}$mice were analyzed for their cytokine and chemokine expression pattern. Stimulation of $\mathrm{T}$ cells with cytokines and chemokines produced by stromal cells influenced their gut-homing phenotype and proliferation. Furthermore, stromal cells of transplanted peripheral lymph nodes (pLNtx) reduced colitis severity in $\mathrm{B} 6-\mathrm{Ill1} \mathrm{O}^{-/-}$mice. In conclusion, lymph node stromal cells are able to influence the development of chronic inflammation.

\section{MATERIALS AND METHODS}

\section{Animals}

C57BL/6J.129P2-Il10 ${ }^{\mathrm{tm} 1 \mathrm{Cgn}}\left(\mathrm{B} 6-\mathrm{Il}_{10} \mathrm{O}^{-/}\right)$were bred at the Central Animal Facility of the Hannover Medical School and were used at a weight of 18-25 g. Mice were housed in filter-top cages located in a room with a controlled environment and 12 hour light/dark cycle. If not stated otherwise, mice received pelleted diet (Altromin 1324 TPF, Altromin Spezialfutter GmbH \& Co. KG, Lage, Germany) and autoclaved water ad libitum. Animals were monitored according to FELASA recommendations (20) and were proven to be free of infection with common murine pathogens except Pasteurella pneumotropica, Helicobacter hepaticus respectively bilis, $\beta$-haemolytic streptococci, Klebsiella oxytoca, Staphylococcus aureus, murine norovirus, Trichomonas spp., and apathogenic intestinal flagellates. Mice were sacrificed by cervical dislocation at 12 or 20 weeks of age.

\section{Ethical Statement}

This study was conducted in accordance with German law for animal protection and with the European Directive 2010/63/EU. All experiments were approved by the Local Institutional Animal Care and Research Advisory committee and permitted by the local government (No. 09/1667, 11/0643, and 20/3451).

\section{Intestinal Surgery and LN Transplantation}

$\mathrm{mLN}$ and $\mathrm{pLN}$ from B6-Il10 ${ }^{-/-}$donor mice were isolated and disrupted. Under the combined anesthesia with ketamine (Gräub AG, Bern, Switzerland) and Domitor (Pfizer, Karlsruhe, Germany) all $\mathrm{mLN}$ of the small and large intestine from recipient $\mathrm{B} 6-\mathrm{IllO}^{-/-}$mice were excised and previously isolated mLN or pLN (axillary, brachial, popliteal, and inguinal LN) from donor mice were transplanted into the mesentery (12). The recipients were sacrificed 8 weeks after transplantation and the transplanted LN (LNtx) were analyzed.

\section{Chronic Colitis Induction}

Chronic colitis was induced using 3.3\% DSS (MP Biomedicals, Eschwege, Germany) in the drinking water for 4 days. Four weeks after DSS-induced colitis, mice were sacrificed and the LN were analyzed.

\section{Preparation of a Single-Cell Suspension From the Small Intestine}

The small intestine was removed and rinsed with PBS. Subsequently, Peyer's patches (PPs) were removed and the small intestine was cut open and sliced into thick section slices. These pieces were minced and then placed into a Hanks Salt solution (Biochrom) containing 2 mM EDTA (Serva, Heidelberg, Germany), $1 \mathrm{mM}$ DL-Dithiothreitol (Sigma), and 5\% FCS for 20 minutes at $37^{\circ} \mathrm{C}$. The suspension was subsequently filtered. This procedure was repeated three times. These first cell suspensions including epithelial cells were collected and pooled. Remaining 
slices were incubated in Hanks Salt solution containing $1.5 \mathrm{mg} /$ $\mathrm{ml}$ collagenease VIII (Sigma-Aldrich, St. Louis, USA) and 5\% FCS. This second cell suspension was also filtered and added to the first collected cell suspension. Cells were collected by centrifugation. After centrifugation cells were counted and analyzed by flow cytometry.

\section{Preparation of a Single-Cell Suspension From $\mathrm{mLN}$}

The whole $\mathrm{mLN}$ string of $\mathrm{B} 6-1110^{-/-}$mice were removed and $\mathrm{LN}$ were digested at $37^{\circ} \mathrm{C}$ for $30 \mathrm{~min}$ with $1 \mathrm{mg} / \mathrm{ml}$ collagenase VIII (Sigma-Aldrich) in RPMI 1640 containing 10\% FCS. CD45 cells were isolated using the MACS technique following the instructions provided by Miltenyi (Bergisch-Gladbach, Germany).

\section{Isolation of $\mathrm{mLN}$ Stromal Cells}

For isolation of CD45- SCs, the small intestine draining mLN (simLN) or the colon draining mLN (cmLN) of macroscopically healthy and colitongenic B6-Il10 $0^{-/-}$mice were removed as described recently $(21,22)$. $\mathrm{LN}$ were digested at $37^{\circ} \mathrm{C}$ for $30 \mathrm{~min}$ with $1 \mathrm{mg} / \mathrm{ml}$ collagenase VIII (Sigma-Aldrich) in RPMI 1640/10\% FCS. CD45cells were isolated using the MACS technique following the instructions provided by Miltenyi (Bergisch-Gladbach, Germany). The isolated SCs were used for mRNA isolation.

\section{Isolation and Stimulation of T Cells}

Cell suspensions from the spleen of B6-Il10/- mice were made and erythrocytes were lysed as described previously (23). Splenic T cells were isolated by negative selection using magnetic cell separation. Therefore, cell suspension was incubated with anti-MHCII (BD Biosciences) and IgG beads (MACS, Miltenyi) each for $20 \mathrm{~min}$. Isolated cells were stained with CFSE $(5 \mathrm{mmol})$ for $2 \mathrm{~min}$ and washed with MACS buffer. Next, $2 \times 10^{6}$ cells/well were cultured with or without anti-CD3 antibody (Biolegend) for 48 hours in RPMI medium (Biochrom, Berlin, Germany) with 10\% FCS (GE Healthcare Life Sciences, Buckinghamshire, UK), 1\% Pen/Strep (Gibco, Thermo Fisher Scientific, Waltham, USA), $0.3 \mathrm{mg} / \mathrm{ml}$ Glutamin (Biochrom), and $10 \mu \mathrm{M} \beta$-mercaptoethanol containing recombinant protein (770 ng/mL CCL5/RANTES $134 \mathrm{ng} / \mathrm{mL}$ CCL2, $200 \mathrm{ng} / \mathrm{mL}$ CCL7, and $150 \mathrm{ng} / \mathrm{mL}$ CXCL16; all Peprotech) for stimulation. Stimulation experiments were performed in duplex and data were generated from 2-5 independent experiments.

\section{Histology}

Colon samples were fixed in neutral buffered $4 \%$ formalin, embedded in paraffin, sectioned at 5-6 $\mu \mathrm{m}$, and stained with hematoxylin and eosin. Histology slides were blindly scored for ulceration, hyperplasia, severity, and the involved area as described previously (2). Briefly, each parameter was graded from physiological (0) to severe changes (3) and added in a total score from 0 to 12 . Colon sections were scored separately for the proximal, middle, and distal part. A total colon score was calculated by adding all three colon sections.

\section{Antibodies for Flow Cytometry}

Stromal cells were analyzed using anti-CD45-PE-Cy7, antiCD21/35-APC (BD Biosciences, Heidelberg, Germany), anti-
Podoplanin-FITC (gp38; Biozol, Eching, Germany), antiCD31-APC (Biolegend, San Diego, USA), and anti-Lyve-1 (kindly provided by R. Förster, Institute of Immunology, Hannover Medical School, Germany) detected by a Cy3coupled goat anti-rabbit antibody (Dianova, Hamburg, Germany). Activation of stromal cells was determined using anti-MHCII-PE, anti-CD54-PE (BD Biosciences), and antiCD106-PE (Serotec).

Cell suspensions from $\mathrm{mLN}$ and the small intestine were prepared as described above. In addition, $1 \times 10^{6}$ cells from $\mathrm{mLN}$ and the small intestine were incubated with anti-CD3FITC, anti-F4/80-APC (both from Biolegend), anti-CD8-PE-Cy7, anti-CD4-APC, anti-IgA-PE (all from Serotec, Oxford, UK), antiCD19-APC-H7, anti-LPAM1-PE, anti-CD11c-FITC (all acquired from BD Biosciences), and anti-CCR9-PE (eBiosciences). All FACS analyses were performed on a FACSCanto (BD Biosciences) and analyzed using Diva software (BD Biosciences) or Kaluza software (Beckmann Coulter).

\section{Quantification of mRNA Expression}

The total RNA was isolated from snap frozen mLN according to the manufacturer's protocol (Bioline, London, UK). The cDNA synthesis was performed with $50 \mu \mathrm{M}$ oligo primer, $0.1 \mathrm{M} \mathrm{DTT}, 5 \mathrm{x}$ first strand buffer, $10 \mathrm{mM}$ dNTP mix, $40 \mathrm{U} / \mu \mathrm{l}$ Rnase inhibitor, and $200 \mathrm{U} / \mu \mathrm{l}$ Superscript III reverse transcriptase (all obtained from Invitrogen) in a total volume of $20 \mu \mathrm{l}$ at $50^{\circ} \mathrm{C}$ for $50 \mathrm{~min}$. Obtained cDNA was used for quantitative real time PCR (qPCR). For SYBR Green ${ }^{\circledR}$ chemistry analyses QuantiTect SYBR Green protocol from Qiagen was used according to the manufacturer's recommendations. The primer sequences and amplicon sizes of Tnfa (5'- GACCCTCACACTCAGATCATCTTC -3' and 5'CGCTGGCTCAGCCACTCC -3'; 104 bp), Il4 (5'- ACGAGG TCACAGGAGAAGGGA $-3^{\prime}$ and $5^{\prime}$ - AGCCCTACAGACGA GCTCACTC -3'; 129 bp), and $\beta$-actin (5'- AGCCATGTA CGTAGCCATCC $-3^{\prime}$ and $5^{\prime}$ - CTCTCAGCTGTGGTGGTGAA $\left.-3^{\prime} ; 228 \mathrm{bp}\right)$ were used. QPCR analyses were performed in CFX Real Time PCR Detection System (Biorad). The amplified PCR product was verified by melting curve analysis. TaqMan ${ }^{\circledR}$ chemistry analyses were performed using TaqMan ${ }^{\circledR}$ Gene Expression Assays (ThermoFisher Scientific) for $\mathrm{Ccl} 7$ (Mm00443113_m1), Ccl2 (Mm00441242_m1), Cxcl16 (Mm00469712_m1), Ccl5 (Mm01302427_m1), and $\beta$-actin (Mm_00607939_s1). Detection was performed with QuantStudio 6 Flex Real-Time PCR System (Applied Biosystems, Weiterstadt, Germany) using the TaqMan ${ }^{\circledR}$ Fast Advanced Master Mix according to the manufacturer's instruction. $\beta$-actin was used as a reference gene in both assays. All reactions were run in triplicate. Relative gene expression was calculated using the $2^{-\Delta \mathrm{Ct}}$ method if not stated otherwise.

\section{Magnetic Cytokine Assays}

The cytokine levels of IL1b, IL2, IL4, IL5, IL6, IL12(p40), IL12 (p70), IL13, IL17, G-CSF, IFNg, MCP1, RANTES, and TNFa were measured in the supernatants of $\mathrm{T}$ cell stimulation experiments or in serum using Bio-Plex Pro cytokine assays (Bio-Rad, Hercules, USA). The assay was performed according to the manufacturer's instructions. 


\section{Data Analysis}

Calculations, statistical analysis, and graphs were made with the software Graphpad Prism 8.0 (Graphpad Software Inc., San Diego, USA). Statistical differences were calculated using unpaired t-test when comparing two groups and one-way analysis of variance (ANOVA) with Tukey's test for multiple comparisons when comparing three or more groups. Statistically significant differences are indicated by ${ }^{*}, \mathrm{P}<0.05 ;{ }^{* *}, \mathrm{P}<0.01$; ${ }^{* * *}, \mathrm{P}<0.001$; $* * * *, \mathrm{P}<0.0001$.

\section{RESULTS}

\section{Intestinal Inflammation Alters Immune Activation of $\mathrm{mLN}$ Stromal Cells}

The development of spontaneous colitis in $I l 10^{-/-}$mice strongly depends on the microbiota composition $(3,4)$. To cause a reproducible colitis onset in our model, mice were exposed to 3.3\% DSS in the drinking water for four days. Four weeks after DSS-induced colitis onset, mice were sacrificed and colitis severity was analyzed. Various inflammatory parameters such as IL17, GCSF, and IL12p40 were increased in serum pointing to a high-grade inflammation (Figure 1A). As the intestinal inflammation in $I l 10^{-/-}$ mice mainly affects the large intestine, we analyzed histopathological changes in the colon. The colon of $\mathrm{B} 6-\mathrm{IlIO}^{-/-}$mice was severely inflamed (Figure 1B). The intestinal pathology was characterized by severe infiltrations of immune cells up to L. muscularis, severe mucosal architecture loss, extended ulcerations, and peritonitis (Figure 1B). Furthermore, all gut draining $\mathrm{LN}$ and the small intestine were analyzed via flow cytometry (Supplementary Figures 1 and 2). The mLN showed decreased percentages of gut homing molecules on $\mathrm{CD}^{+}{ }^{+} \mathrm{T}$ cells and $\mathrm{B}$ cells (Figure 1C). In the small intestine $\mathrm{T}$ cells as well as $\mathrm{IgA}^{+} \mathrm{B}$ cells were increased, whereas DC and macrophages were decreased (Figure 1C). Furthermore, we detected decreased podoplanin ${ }^{+}\left(\mathrm{Gp} 38^{+}\right)$and also Lyve- ${ }^{+}$cells in mLN (Figure 1D). Podoplanin ${ }^{+}$as well as CD21/35 ${ }^{+}$cells showed increased MHC class II expression suggesting that these cells are activated. Also CD106 was highly expressed on podoplanin ${ }^{+}$cells. In contrast, $\mathrm{CD} 21 / 35^{+}$cells showed reduced expression of CD106 as well as CD54 (Figure 1D). Thus, these results showed that intestinal inflammation in B6-Il10/- mice affects the whole intestinal tract including $\mathrm{mLN}$ and especially mLN stromal cells.

\section{CCL7 and CXCL16 Activate T Cells During Inflammation}

Various chemokines such as CCL2, CCL5, CCL7, or CXCL16, which are important for recruitment and organization of $\mathrm{T}$ cells and DC or after induction of inflammation, were shown to be produced by stromal cells $(15,16)$. Therefore, we measured the gene expression of these genes in CD45- stromal cells isolated from small intestine draining (si) $\mathrm{mLN}$ or colon draining (c) $\mathrm{mLN}$ of control and inflamed B6-Il10 $0^{-/-}$mice by qPCR. The gene expression of $\mathrm{Ccl} 2, \mathrm{Ccl}$, and $\mathrm{Cxcl16}$ was increased in colitogenic $\mathrm{cmLN}$ stromal cells. Stromal cells isolated from simLN showed also differences in gene expression of $\mathrm{Ccl} 2$ and $\mathrm{Ccl} 7$, although to a lower extent. Expression of Cxcl16 was unchanged in simLN stromal cells of mice suffering from colonic inflammation (Figure 2). Expression of Ccl5 was unaltered in healthy and colitogenic stromal cells isolated from simLN and cmLN. Subsequently, we isolated T cells from the spleen and cultured them without or with these chemokines (CCL2, CCL5, CCL7, and CXCL16) for 48 hours. Upon chemokine stimulation, activation (induction of gut homing molecules) and proliferation (CFSE staining) of $\mathrm{T}$ cells were detected using flow cytometry (Supplementary Figure 3). Stimulation experiments were performed in duplex and data were generated from 2-5 independent experiments. Each chemokine stimulation was performed independent from the others to exclude chemokine contamination. Upon CCL2 stimulation, no differences in T cell proliferation and activation dependent on CCL2 were found (Figure 3A). However, in the supernatant of CCL2 and CD3 costimulated $\mathrm{T}$ cells increased levels of IL2 were measured (Figure 3B). $\mathrm{CD}^{+}$and $\mathrm{CD} 8^{+} \mathrm{T}$ cells stimulated only with CCL5 showed decreased activation and proliferation. After co-stimulation with $\mathrm{CD} 3$, only proliferation in $\mathrm{CD}^{+} \mathrm{T}$ cells was decreased (Figure 3A). However, increased levels of TNF $\alpha$, IL12p70, G-CSF, and MCP-1 (CCL2) in the supernatants of CCL5 and CD3 co-stimulated T cells were detected (Figure 3B). In addition, these cells showed decreased levels of IFN $\gamma$ (Figure 3B). The co-stimulation of $\mathrm{T}$ cells with recombinant CCL7 and CD3 resulted in activated $\mathrm{T}$ cells. We detected higher percentages of $\mathrm{CD} 25^{+}$and $\mathrm{CCR}^{+} \mathrm{CD}^{+} \mathrm{T}$ cells (Figure 3A). These cells also produced higher levels of IL2 and IL17 as detected in the supernatants of the cultured cells (Figure 3B). Furthermore, we measured higher percentages of $\mathrm{CFSE}^{+}$cells after stimulation with CXCL16/CD3 among $\mathrm{CD}^{+} \mathrm{T}$ cells (Figure 3A). In the supernatants of these co-stimulated cells, we measured increased levels of RANTES (CCL5) and decreased concentrations of IL2 (Figure 3B). Together, these results indicate that T cell activation could be influenced by chemokines produced by lymph node cells including stromal cells.

\section{PLN Stromal Cells Reduce Severity of Chronic Colitis}

We and others already described earlier that stromal cells from pLN express a different cytokine and chemokine pattern than $\mathrm{mLN}$ stromal cells $(18,24)$. Furthermore, pLN transplanted (pLNtx) mice showed decreased antigen specific $\operatorname{IgA}^{+} \mathrm{B}$ cells after cholera toxin administration compared to mesenteric lymph node transplanted (mLNtx) mice, as well as alterations in oral tolerance induction. Therefore, we transplanted $\mathrm{pLN}$ of $\mathrm{B} 6-\mathrm{IlIO}^{-/-}$mice in the mesentery of B6-Il10 ${ }^{-/-}$mice. After a regeneration phase of eight weeks, colitis in B6-Il10 ${ }^{-/-}$mice was triggered by administration of 3.3\% DSS in the drinking water for four days. After DSS treatment mice received water ad libitum for subsequent four weeks. The colon histopathological score was lower in pLNtx than in mLNtx mice (Figure 4A). The intestinal inflammation in mLNtx mice was characterized by moderate to marked infiltrations of immune cells up to L. muscularis, erosions of the epithelium, and moderate to marked architecture loss. Furthermore, increased IL4 levels in serum (Figure 4B) and increased Tnfa and Il4 expression (Figure 4C) were detected in pLNtx mice. Although we did not find any differences in the lymphocytes compartment, we observed an increased percentage of podoplanin ${ }^{+}$cells in pLNtx mice. 

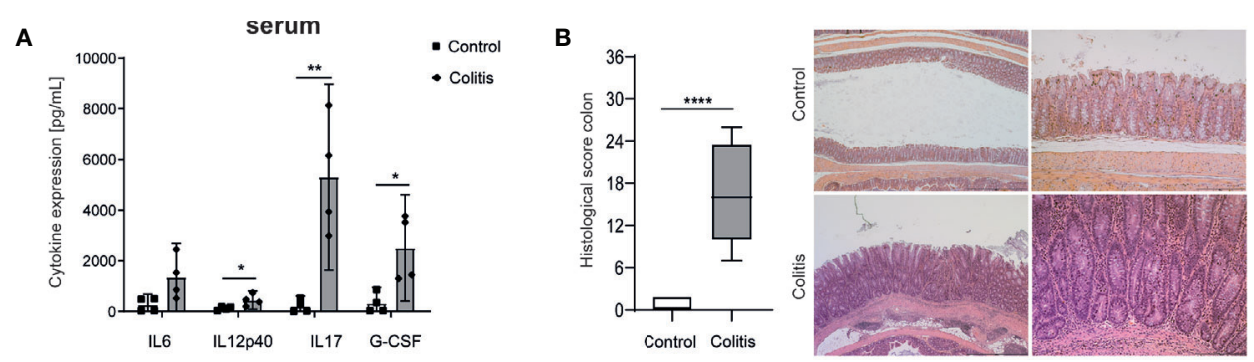

C
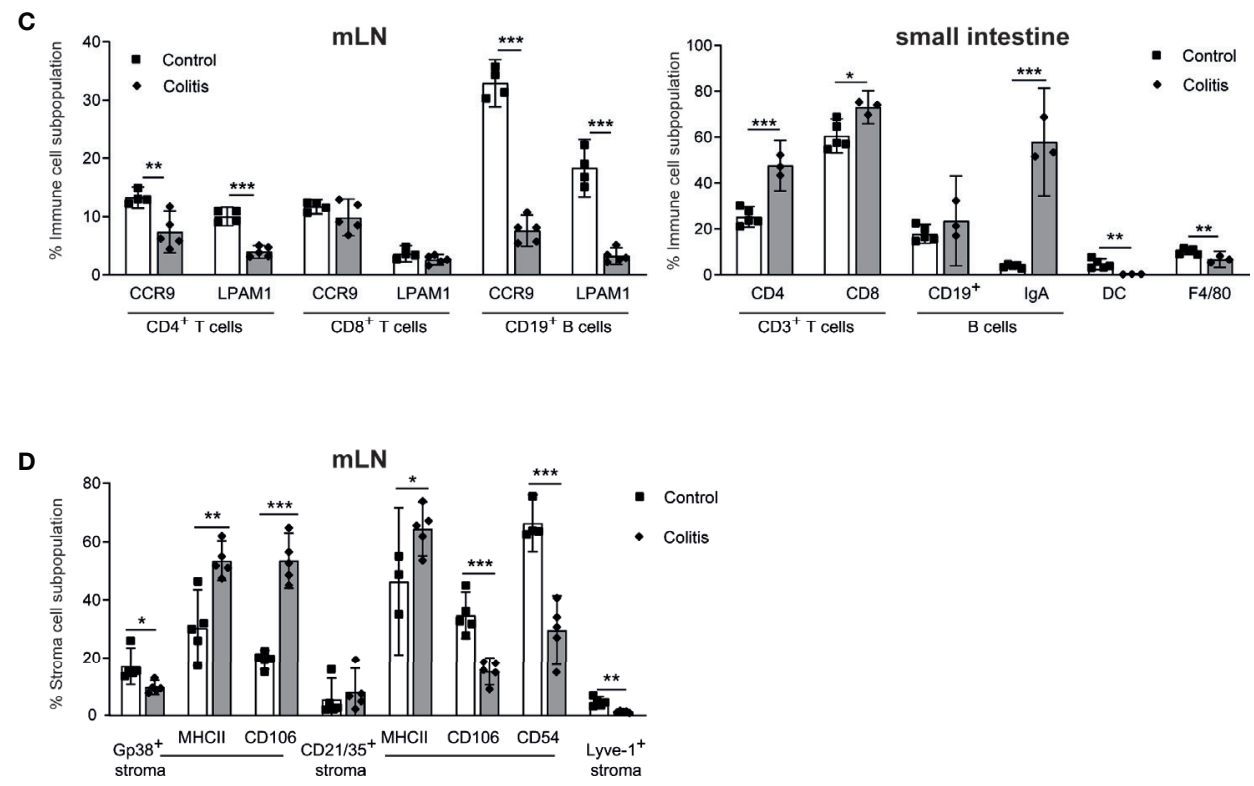

FIGURE 1 | Impact of chronic intestinal inflammation on the gut and $\mathrm{mLN}$ cell compartments. (A) Levels of pro-inflammatory cytokines measured in serum of control and inflamed B6- $/ 110^{-1-}$ mice (filled squares: control, filled diamonds: colitis). Data were shown as mean \pm 95\% confidential intervals ( $\mathrm{n}=4$ ). (B) Histopathological score quantifying alterations observed in the colon of B6- $/ / 10^{-/-}$control and inflamed (animals in which chronic colitis was triggered by DSS) mice. Data presented in box and whiskers plots are the medians with minimum and maximum ( $n=5-7)$. Representative images of hematoxylin and eosin stained colon sections of 12 -week-old control (upper panels) and inflamed (lower panels) B6- $1 / 10^{-1-}$ mice (magnification left panels: 2.5x; magnification right panels: 10x). (C) Flow cytometry analysis of single cell suspensions from $\mathrm{mLN}$ and the small intestine of control and inflamed B6-//10 ${ }^{-1-}$ mice (filled squares: control, filled diamonds: colitis). Plots summarize frequencies of immune cell populations in $\mathrm{mLN}\left(\mathrm{CD} 4^{+} \mathrm{T}\right.$ cells, CD8 ${ }^{+} \mathrm{T}$ cells, and CD19+ B cells) and the small intestine (CD3 ${ }^{+} \mathrm{T}$ cells, B cells, DCs and F4/80 ${ }^{+}$macrophages). Data were shown as mean $\pm 95 \%$ confidential intervals $(n=3-5)$. (D) Flow cytometry analysis of single cell suspensions from $\mathrm{mLN}$ of control and inflamed B6-//10 ${ }^{-/}$mice (filled squares: control, filled diamonds: colitis). Plots summarize frequencies of stromal cell populations (Gp38 ${ }^{+}, \mathrm{CD}_{21 / 35^{+}}$, and Lyve- $1^{+}$stromal cells). Data were shown as mean $\pm 95 \%$ confidential intervals $(n=3-5)$. Statistically significant differences are indicated by ${ }^{\star}, P<0.05 ;{ }^{\star \star}, P<0.01 ;{ }^{\star \star \star}, P<0.001 ;{ }^{\star \star \star \star}, P<0.0001$.

Podoplain $^{+}$cells from pLNtx mice expressed less MHC class II molecules than podoplain ${ }^{+}$cells from mLNtx mice (Figure 4D). Furthermore, we observed increased expression of activation markers, CD106 and CD54, on CD21/35 ${ }^{+}$cells in pLNtx mice (Figure 4D). Thus, pLN stromal cells seem to induce an altered immune reaction during colitis development in $\mathrm{B} 6-\mathrm{Il}^{-/-}$mice, resulting in a decreased disease severity.

\section{DISCUSSION}

In the past 10 years, lymph node stromal cells came into focus for immunologists, as these cells were shown to influence immune response and tolerance induction. In this study we show that stromal cells could impact the development of chronic colitis via $\mathrm{T}$ cell induction.
The $1110^{-/-}$mouse model was engineered in 1993 by Kühn and colleagues (1). These mice are also widely used as a model of experimental IBD. Under conventional barrier conditions, these animals develop a chronic enterocolitis associated with anemia, splenomegaly, and weight loss. Histologically, the disease is characterized by transmural, mononuclear, and granulomatous infiltrations, crypt abscesses, erosions, or focal ulcerations. With the progression of the intestinal inflammation, thickened colon wall, hyperplasia, or loss of the crypt architecture occurs. All parts of the lower gastrointestinal tract including colon, caecum, and small intestine can be affected (25). In this study B6-Il10-1mice showed a severe intestinal inflammation affecting the whole intestinal tract including small intestinal and colon draining $\mathrm{mLN}$. Increased levels of pro-inflammatory cytokines, reduced effector T and B cells in the $\mathrm{mLN}$, but also increased $\operatorname{IgA}^{+} \mathrm{B}$ cells and $\mathrm{CD}^{+}$and $\mathrm{CD}^{+} \mathrm{T}$ cells in the intestine were detected. The 
A

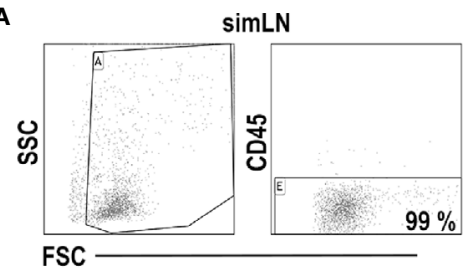

B

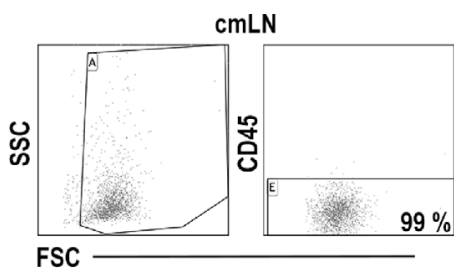

$\mathrm{Ccl} 2$

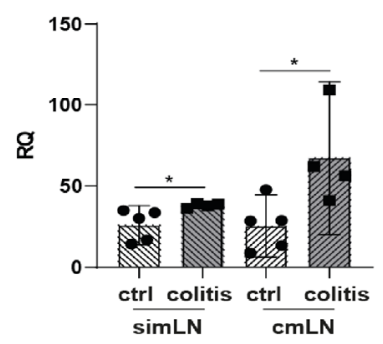

$\mathrm{Ccl7}$

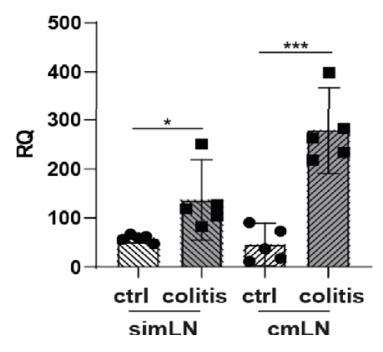

$\mathrm{CcI5}$

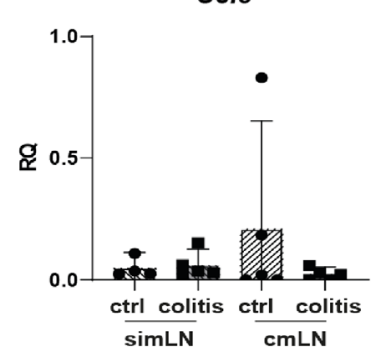

Cxcl16

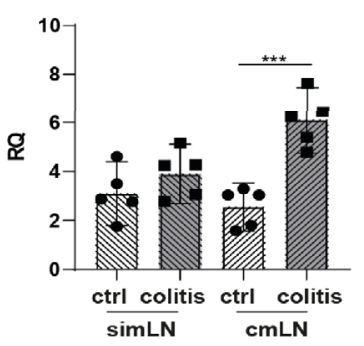

FIGURE 2 | The intestinal inflammation alters expression of chemokines in $\mathrm{mLN}$-derived stromal cells. Stromal cells were isolated from healthy and colitogenic small intestine draining or colon draining $\mathrm{mLN}$. (A) Representative Dot Plots of CD45 negative cell enrichment obtained after selection procedure. (B) Gene expression of chemokines $\mathrm{Ccl} 2, \mathrm{Cc} / 5, \mathrm{Ccl}$, and $\mathrm{Cxc} / 16$ measured by $\mathrm{QPCR}$ in total RNA isolated from small intestine draining or colon draining mLN stromal cells of control and inflamed B6-II10 $/-$ mice (filled circles: control, filled squares: colitis). Relative differences in gene expression were calculated by the relative quantification (RQ) method $\left(2^{-\Delta \Delta C t}\right.$ method) using a reference sample and housekeeping gene for normalization of gene expression. Data were shown as mean $\pm 95 \%$ confidential intervals $(n=4-5)$. Statistically significant differences are indicated by ${ }^{*}, P<0.05 ;{ }^{* \star}, P<0.001$.

anti-inflammatory cytokine IL10 is produced by a variety of cells including T and B cells, DC and macrophages (4, 25). IL10 is important to negatively regulate the innate as well as the adaptive immune system $(26,27)$. The deficiency of IL10 leads to an increased DC activity and an enhanced T effector cell induction. The excessive adaptive immune response in the $1110^{-/-}$model was initially identified as a Th1 response $(1,28)$. However, several other studies also support the contribution of a Th17 lineage $(26,29)$.

Besides building the backbone of the LN, SCs were shown to be involved in tolerance induction as well as inflammatory responses $(7,12,15,16,18,19,30)$. LNSCs enhance the expression of genes encoding inflammatory cytokines, TLR4 signaling, and MHC class II genes after LPS stimulation (15), viral infection (31), or Yersinia pseudotuberculosis infection (16). In our study, we showed that mLN-derived stromal cells can play a role in the development of chronic colitis. Podoplanin ${ }^{+}$cells as well as FDCs showed increased surface expression of MHC class
II molecules. Moreover, strong upregulation of CD106 on podoplanin ${ }^{+}$cells suggests an increased $\mathrm{T}$ cell-FRC contact during inflammation.

FRCs were shown to directly interact with $\mathrm{T}$ cells producing IL7 or CCL19/21 to promote survival $(32,33)$, migration, and Treg induction (19). Therefore, we hypothesized that cytokines or chemokines produced by FRCs directly activate T cells during inflammation. Chemokines such as $\mathrm{Ccl} 2, \mathrm{Ccl} 5, \mathrm{Ccl} 7$, and $\mathrm{Cxcl16}$ were shown to be expressed by lymph node stromal cells $(15,16)$. As shown previously, mLN consists of various lymph nodes, which drain different regions of the intestine $(21,22)$. Therefore, we isolated stromal cells from the smLN as well as cmLN and measured the expression of these chemokines. All chemokines were increased in stromal cells isolated from inflamed $\mathrm{cmLN}$ except Ccl5. To determine the impact of these chemokines on $\mathrm{T}$ cell, we isolated T cells, treated them with cytokines/chemokines, and analyzed the proliferation and cytokine secretion after 48 hours. Although we expected an activation of T cells after CD3 

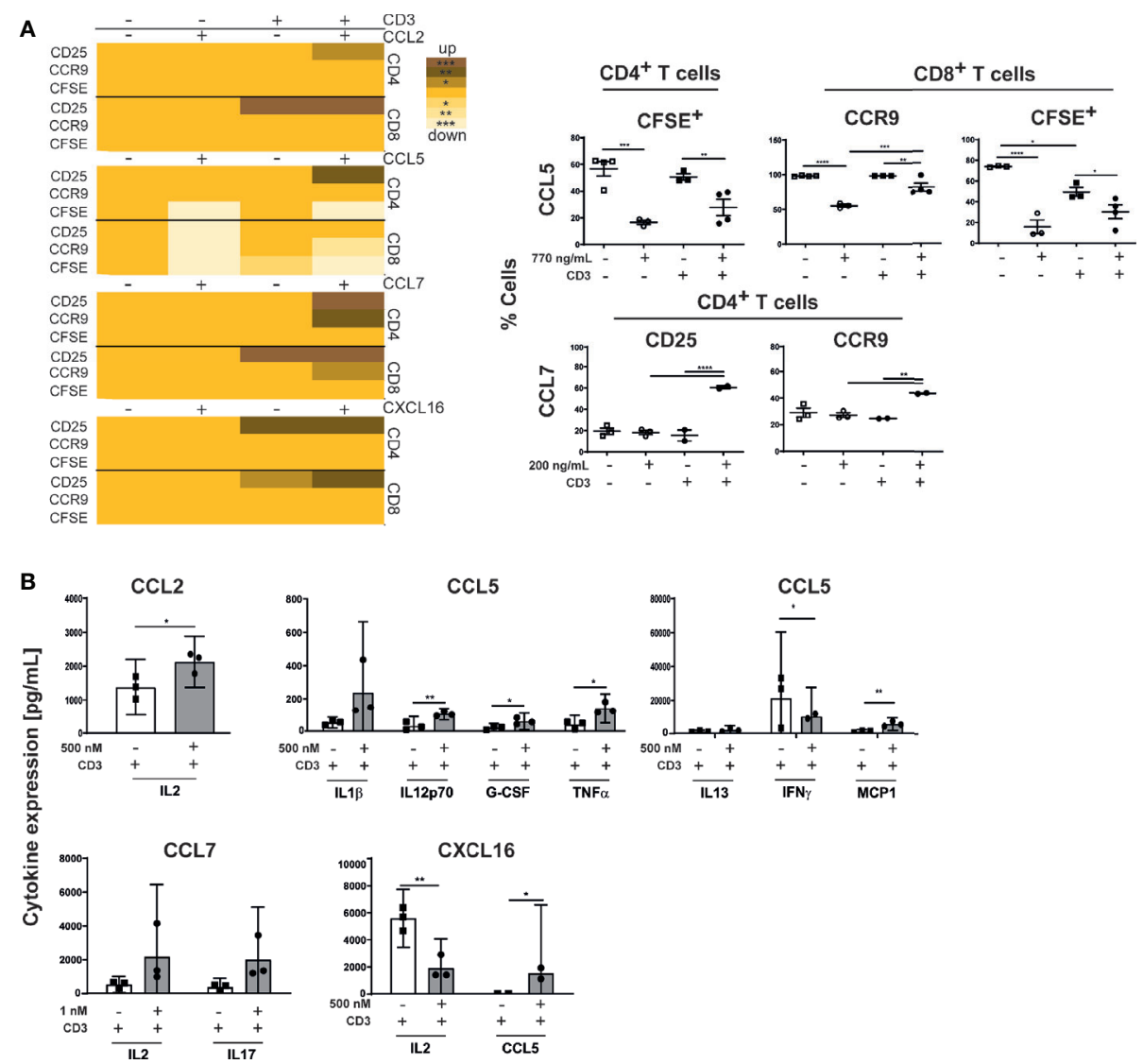

FIGURE 3 | Chemokine stimulation influence activation and proliferation of B6-/I10 $0^{-/-}$splenic T cells. (A) Isolated splenic T cells were stimulated with chemokines and/or CD3 for 48 hours and proliferation and expression of gut-homing molecules on $\mathrm{CD}^{+}$and $\mathrm{CD} 8^{+} \mathrm{T}$ cells was detected using flow cytometry. Heat map shows the significant differences of T cell activation and proliferation after CD3 and chemokine stimulation (CCL2, CCL5, CCL7, or CXCL16). Scatterplots, showing differences dependent on chemokine stimulation, summarize frequencies of $\mathrm{CD}_{2} 5^{+}, \mathrm{CCR}^{+}$, and $\mathrm{CFSE}^{+} \mathrm{T}$ cells upon stimulation with chemokine, and co-stimulation with CD3 (open squares: control, open circles: chemokine stimulation, filled squares: CD3 stimulation, filled circles: CD3/chemokine co-stimulation). Plotted are mean values of two replicates from 2-5 independent experiments. Data were shown as mean \pm SEM. (B) Levels of expressed cytokines/chemokines detected in the supernatant of T cells stimulated only with specific chemokine (CCL2, CCL5, CCL7, or CXCL16) or co-stimulated with CD3 isolated from B6-/l10 ${ }^{-/}$mice (filled squares: CD3 stimulation, filled circles: CD3/chemokine co-stimulation). Plotted are single values from 2-3 independent experiments. Data were shown as mean \pm confidential intervals $(n=2-3)$. Statistically significant differences are indicated by ${ }^{*}, P<0.05 ;{ }^{* \star}, P<0.01 ;{ }^{* \star \star}, P<0.001 ;{ }^{* \star \star \star}, P<0.0001$.

stimulation alone, we were not able to detect an increase in CD25 expression in all analyzed stimulation settings. We hypothesize that this could be due to the health status of $I l 10^{-/-}$mice. The isolated $\mathrm{T}$ cells could be activated in vivo due to low-level inflammation already existing in $1110^{-/-}$mice, thus, additional activation with $\mathrm{CD} 3$ could not be achieved in the performed stimulation assay. Stimulation with CXCL16 and CCL7 activated $\mathrm{T}$ cells as observed in increased proliferation or CD25 expression, respectively. CCL7 was shown to induce migration of various leukocytes including monocytes and lymphocytes (34), while soluble CXCL16 is a strong chemoattractant for CXCR6 ${ }^{+} \mathrm{T}$ cells (35). Furthermore, CCL7 and CXCL16 were found to be increased in the intestine of IBD patients as well as in mouse models of experimental colitis $(18,36)$. Both chemokines seem to be involved in $\mathrm{T}$ cell activation and migration leading to exacerbated intestinal inflammation. However, stimulation with most of the cytokines/chemokines did not activate $\mathrm{T}$ cells, suggesting that there is another cell population interacting with LNSCs. Potential candidate lineage could be DCs, as stromal cells were shown to induce tolerogenic DCs in mLN (16). Stromal cells from different draining areas can influence immune cells in a different way. Using a lymph node transplantation model, in which pLN were transplanted into mesentery, we previously showed that oral tolerance in pLNtx mice is induced via B cells in contrast to Treg induction in endogenous mLN (12). Moreover, $\mathrm{mLN}$ transplanted into the periphery are more efficient in Treg induction as the endogenous LN (19). Therefore, this model enables us to analyze the influence of stromal cells on immune response. In this study, pLN transplanted into the mesentery resulted in increased gene and protein expression of IL4, and a decreased disease severity. IL4 is a Th2 cytokine that inhibits T cell differentiation into Th1 and Th17 phenotype. As colitis in 
A
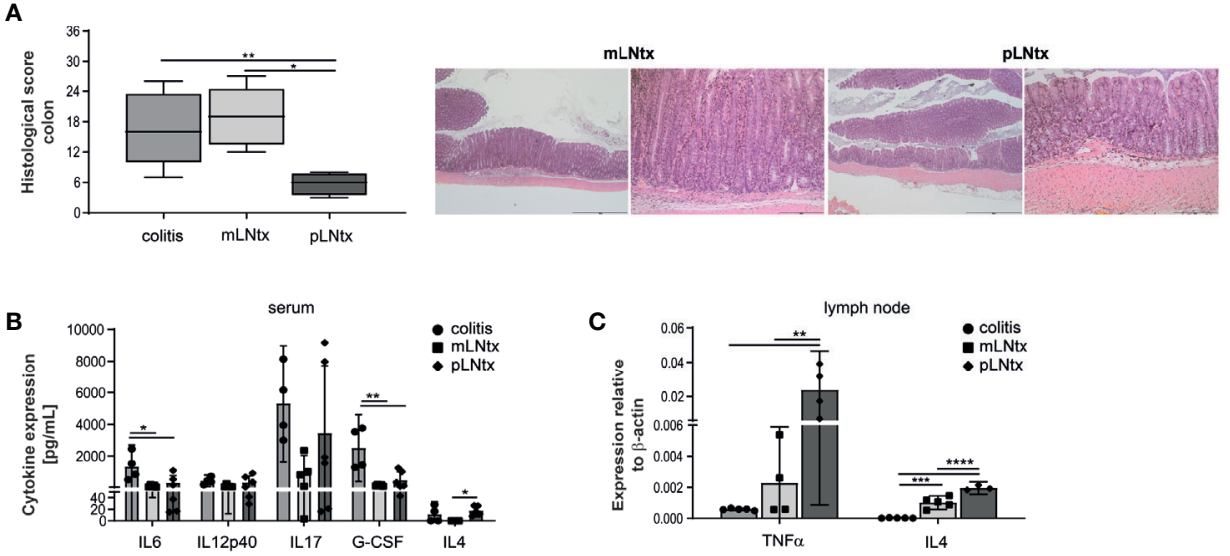

D
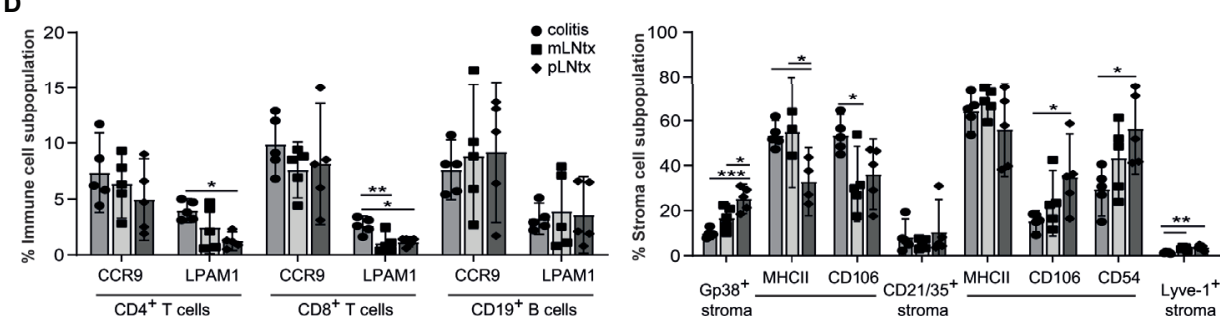

FIGURE 4 | Stromal cells from pLN attenuate the severity of chronic colitis. (A) Histopathological score quantifying alterations observed in the colon tissue of 20week-old B6- $/ / 10^{-/-}$mice after transplantation of pLN (pLNtx) or $\mathrm{mLN}\left(\mathrm{mLNtx}\right.$ ) into the mesentery and inflamed B6-//10 ${ }^{-/-}$mice (as already shown in Figure 1A). Data presented in box and whiskers plots are the medians with minimum and maximum $(n=4-5)$. Representative images of hematoxylin and eosin stained colon sections of mLNtx and pLNtx B6-//10 ${ }^{-/-}$mice (mLNtx magnification left panel: 2.5x, right panel: 10x; pLNtx magnification left panel: 2.5x, right panel: 10x). (B) Levels of proinflammatory cytokines measured in serum of inflamed B6- $/ 10^{-/-}$mice and $\mathrm{mLNtx}$ and pLNtx B6- $/ / 10^{-1-}$ mice (filled circles: colitis, filled squares: $\mathrm{mLNtx}$, filled diamonds: pLNtx). Data were shown as mean $\pm 95 \%$ confidential intervals ( $n=3-5)$. (C) Gene expression of Tnfa and $/ 14$ measured by qPCR in total RNA isolated from $\mathrm{mLN}$ of inflamed B6- $/ / 10^{-/-}$mice and $\mathrm{mLNtx}$ and pLNtx B6- $/ 110^{-/-}$mice (filled circles: colitis, filled squares: $\mathrm{mLNtx}$, filled diamonds: pLNtx). Relative differences in gene expression were calculated by the comparative $2^{-\delta C t}$ method. Data were shown as mean $\pm 95 \%$ confidential intervals ( $\mathrm{n}=3-5$ ). (D) Flow cytometry analysis of

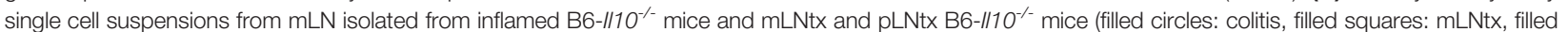
diamonds: pLNtx). Plots summarize frequencies of immune cell populations (CD4 ${ }^{+} \mathrm{T}$ cells, CD8 ${ }^{+} \mathrm{T}$ cells, and CD19 ${ }^{+} \mathrm{B}$ cells) and stromal cell populations $\left(\mathrm{Gp} 38^{+}\right.$, CD21/35+, and Lyve- $1^{+}$stromal cells) isolated from $\mathrm{mLN}$. Data were shown as mean $\pm 95 \%$ confidential intervals ( $\left.\mathrm{n}=3-5\right)$. Statistically significant differences are indicated by *, $\mathrm{P}<0.05 ;{ }^{* \star}, \mathrm{P}<0.01 ;{ }^{* \star \star}, \mathrm{P}<0.001 ;{ }^{* \star \star *}, \mathrm{P}<0.0001$.

$I l 10^{-/-}$mice is dependent on Th1 and Th17 immune responses, increased expression of IL4 can act as a negative regulator of inflammation. The protective effect of IL4 has been shown in murine models of rheumatoid arthritis and diabetes (37-39). However, $I l 4^{-/-} I l 10^{-/-}$double deficient mice showed decreased colitis induction after DSS treatment (40) indicating that IL4 alone is not sufficient to reduce chronic colitis severity. Further studies need to be performed to evaluate the role of IL4 in chronic inflammation. Nevertheless, pLN stromal cells induce an altered immune response during colitis development in B6- $1110^{-/-}$ mice indicating importance of imprinting processes. As mLN stromal cells acquire their specific immune response induction pattern early during neonatal microbiota colonization, lymph nodes from skin draining area develop different expression patterns (16).

In conclusion, lymph node stromal cells are activated during colitis development. Cytokines expressed by colitogenic stromal cells can influence $\mathrm{T}$ cell activation in vitro. However, stromal cells from lymph nodes of different draining areas regulate induction of immune responses toward neonatally imprinted processes.

\section{DATA AVAILABILITY STATEMENT}

The original contributions presented in the study are included in the article/Supplementary Material. Further inquiries can be directed to the corresponding author.

\section{ETHICS STATEMENT}

The animal study was reviewed and approved by Lower Saxony State Office for Consumer Protection and Food Safety. 


\section{AUTHOR CONTRIBUTIONS}

$\mathrm{MBu}$ and $\mathrm{UB}$ conceived experiments. $\mathrm{MBu}, \mathrm{PPP}$, and $\mathrm{MBo}$ performed experiments. $\mathrm{AB}, \mathrm{MBu}, \mathrm{SB}$, and $\mathrm{MBo}$ analyzed results. $\mathrm{MBu}$ and $\mathrm{MBa}$ interpreted results and wrote the manuscript. All authors contributed to the article and approved the submitted version.

\section{FUNDING}

The work was supported by the German Research Foundation (SFB621/A10) to UB and by the Hannover Medical School project funding program, Hochschulinterne Leistungsförderung HiLF to $\mathrm{MBu}$.

\section{ACKNOWLEDGMENTS}

We would like to acknowledge the assistance of the Cell Sorting Core Facility of the Hannover Medical School supported in part by Braukmann-Wittenberg-Herz-Stiftung and German Research Foundation.

\section{REFERENCES}

1. Kuhn R, Lohler J, Rennick D, Rajewsky K, Muller W. Interleukin-10-deficient mice develop chronic enterocolitis. Cell (1993) 75(2):263-74. doi: 10.1016/ 0092-8674(93)80068-p

2. Bleich A, Mahler M, Most C, Leiter EH, Liebler-Tenorio E, Elson CO, et al. Refined histopathologic scoring system improves power to detect colitis QTL in mice. Mamm Genome (2004) 15(11):865-71. doi: 10.1007/s00335-004-2392-2

3. Hart ML, Ericsson AC, Franklin CL. Differing Complex Microbiota Alter Disease Severity of the IL-10(-/-) Mouse Model of Inflammatory Bowel Disease. Front Microbiol (2017) 8:792. doi: 10.3389/fmicb.2017.00792

4. Keubler LM, Buettner M, Hager C, Bleich A. A Multihit Model: Colitis Lessons from the Interleukin-10-deficient Mouse. Inflammation Bowel Dis (2015) 21(8):1967-75. doi: 10.1097/MIB.0000000000000468

5. Bajenoff M, Egen JG, Koo LY, Laugier JP, Brau F, Glaichenhaus N, et al. Stromal cell networks regulate lymphocyte entry, migration, and territoriality in lymph nodes. Immunity (2006) 25(6):989-1001. doi: 10.1016/j.immuni.2006.10.011

6. Katakai T, Hara T, Lee JH, Gonda H, Sugai M, Shimizu A. A novel reticular stromal structure in lymph node cortex: an immuno-platform for interactions among dendritic cells, T cells and B cells. Int Immunol (2004) 16(8):1133-42. doi: 10.1093/intimm/dxh113

7. Hammerschmidt SI, Ahrendt M, Bode U, Wahl B, Kremmer E, Forster R, et al. Stromal mesenteric lymph node cells are essential for the generation of gut-homing T cells in vivo. J Exp Med (2008) 205(11):2483-90. doi: 10.1084/ jem.20080039

8. Iwata M, Hirakiyama A, Eshima Y, Kagechika H, Kato C, Song SY. Retinoic acid imprints gut-homing specificity on T cells. Immunity (2004) 21(4):52738. doi: 10.1016/j.immuni.2004.08.011

9. Molenaar R, Knippenberg M, Goverse G, Olivier BJ, de Vos AF, O’Toole T, et al. Expression of retinaldehyde dehydrogenase enzymes in mucosal dendritic cells and gut-draining lymph node stromal cells is controlled by dietary vitamin A. J Immunol (2011) 186(4):1934-42. doi: 10.4049/jimmunol.1001672

10. Campbell DJ, Butcher EC. Rapid acquisition of tissue-specific homing phenotypes by $\mathrm{CD} 4(+) \mathrm{T}$ cells activated in cutaneous or mucosal lymphoid tissues. J Exp Med (2002) 195(1):135-41. doi: 10.1084/jem.20011502

11. Pabst O, Ohl L, Wendland M, Wurbel MA, Kremmer E, Malissen B, et al. Chemokine receptor CCR9 contributes to the localization of plasma cells to the small intestine. J Exp Med (2004) 199(3):411-6. doi: 10.1084/ jem.20030996

\section{SUPPLEMENTARY MATERIAL}

The Supplementary Material for this article can be found online at: https://www.frontiersin.org/articles/10.3389/fimmu.2020. 549473/full\#supplementary-material

Supplementary Figure 1 I Surface staining of total cell populations of the $\mathrm{mLN}$ and small intestine from B6-I/10 $0^{-1-}$ mice was performed and analyzed by flow cytometry. Gating strategy for $\mathrm{mLN}$ cells shows CD3+ cells, CD19+ cells gated from the leukocyte gate. CD4+ and CD8+ cells were gated from CD3+ cells. Homing marker CCR9 and LPAM1 were analyzed from CD19+ or CD4+ and CD8+ cells. Gating strategy for cells isolated from small intestine shows CD3+ cells, CD19 + cells, IgA+ cells, MHCll/CD11c+ cells (DC), and MHCll/F4/80+ cells (macrophages) gated from the leukocyte gate. $\mathrm{CD} 4+$ and $\mathrm{CD} 8+$ cells were gated from $\mathrm{CD} 3+$ cells.

Supplementary Figure 2 | Gating strategy for stromal cells analysis. From living cells, CD45- cells were gated and subpopulations were identified using podoplanin+ (gp38), CD21/CD35+ (FDC), and Lyve-1+ (lymphatic endothelial cells) cells. Surface marker MHCIl, CD106, and CD54 were gated from gp38+ cells or CD21/CD35+ cells.

Supplementary Figure 3 | Gating strategy for cytokine stimulated T cells. T cell subpopulations were identified using CD3, CD4, and CD8 antibodies. CFSE as well as CD25+ cells and CCR9+ cells were gated from CD3/CD4+ cells and CD3/CD8+ cells.

12. Buettner M, Pabst R, Bode U. Lymph node stromal cells strongly influence immune response suppression. Eur J Immunol (2011) 41(3):624-33. doi: 10.1002/eji.201040681

13. Buettner M, Dittrich-Breiholz O, Falk CS, Lochner M, Smoczek A, Menzel F, et al. Stromal cells as trend-setters for cells migrating into the lymph node. Mucosal Immunol (2015) 8(3):640-9. doi: 10.1038/mi.2014.97

14. Fletcher AL, Lukacs-Kornek V, Reynoso ED, Pinner SE, Bellemare-Pelletier A, Curry MS, et al. Lymph node fibroblastic reticular cells directly present peripheral tissue antigen under steady-state and inflammatory conditions. J Exp Med (2010) 207(4):689-97. doi: 10.1084/jem.20092642

15. Malhotra D, Fletcher AL, Astarita J, Lukacs-Kornek V, Tayalia P, Gonzalez SF, et al. Transcriptional profiling of stroma from inflamed and resting lymph nodes defines immunological hallmarks. Nat Immunol (2012) 13(5):499-510. doi: $10.1038 /$ ni.2262

16. Pezoldt J, Pasztoi M, Zou M, Wiechers C, Beckstette M, Thierry GR, et al. Neonatally imprinted stromal cell subsets induce tolerogenic dendritic cells in mesenteric lymph nodes. Nat Commun (2018) 9(1):3903. doi: 10.1038/ s41467-018-06423-7

17. Rodda LB, Lu E, Bennett ML, Sokol CL, Wang X, Luther SA, et al. Single-Cell RNA Sequencing of Lymph Node Stromal Cells Reveals Niche-Associated Heterogeneity. Immunity (2018) 48(5):1014-28.e6. doi: 10.1016/j.immuni.2018.04.006

18. Ahrendt M, Hammerschmidt SI, Pabst O, Pabst R, Bode U. Stromal cells confer lymph node-specific properties by shaping a unique microenvironment influencing local immune responses. J Immunol (2008) 181(3):1898-907. doi: 10.4049/jimmunol.181.3.1898

19. Cording S, Wahl B, Kulkarni D, Chopra H, Pezoldt J, Buettner M, et al. The intestinal micro-environment imprints stromal cells to promote efficient Treg induction in gut-draining lymph nodes. Mucosal Immunol (2014) 7(2):35968. doi: $10.1038 / \mathrm{mi} .2013 .54$

20. Mahler Convenor M, Berard M, Feinstein R, Gallagher A, Illgen-Wilcke B, Pritchett-Corning $\mathrm{K}$, et al. FELASA recommendations for the health monitoring of mouse, rat, hamster, guinea pig and rabbit colonies in breeding and experimental units. Lab Anim (2014) 48(3):178-92. doi: $10.1177 / 0023677213516312$

21. Esterhazy D, Canesso MCC, Mesin L, Muller PA, de Castro TBR, Lockhart A, et al. Compartmentalized gut lymph node drainage dictates adaptive immune responses. Nature (2019) 569(7754):126-30. doi: 10.1038/s41586-019-1125-3

22. Houston SA, Cerovic V, Thomson C, Brewer J, Mowat AM, Milling S. The lymph nodes draining the small intestine and colon are anatomically separate 
and immunologically distinct. Mucosal Immunol (2016) 9(2):468-78. doi: $10.1038 / \mathrm{mi} .2015 .77$

23. Westermann J, Smith T, Peters U, Tschernig T, Pabst R, Steinhoff G, et al. Both activated and nonactivated leukocytes from the periphery continuously enter the thymic medulla of adult rats: phenotypes, sources and magnitude of traffic. Eur J Immunol (1996) 26(8):1866-74. doi: 10.1002/eji.1830260830

24. Bode U, Sahle A, Sparmann G, Weidner F, Westermann J. The fate of effector $\mathrm{T}$ cells in vivo is determined during activation and differs for $\mathrm{CD} 4+$ and $\mathrm{CD} 8+$ cells. J Immunol (2002) 169(11):6085-91. doi: 10.4049/jimmunol.169.11.6085

25. Jones-Hall YL, Grisham MB. Immunopathological characterization of selected mouse models of inflammatory bowel disease: Comparison to human disease. Pathophysiology (2014) 21(4):267-88. doi: 10.1016/j.pathophys.2014.05.002

26. Gomes-Santos AC, Moreira TG, Castro-Junior AB, Horta BC, Lemos L, Cruz $\mathrm{DN}$, et al. New insights into the immunological changes in IL-10-deficient mice during the course of spontaneous inflammation in the gut mucosa. Clin Dev Immunol (2012) 2012:560817. doi: 10.1155/2012/560817

27. Skeen MJ, Miller MA, Shinnick TM, Ziegler HK. Regulation of murine macrophage IL-12 production. Activation of macrophages in vivo, restimulation in vitro, and modulation by other cytokines. J Immunol (1996) 156(3):1196-206.

28. Davidson NJ, Leach MW, Fort MM, Thompson-Snipes L, Kuhn R, Muller W, et al. $\mathrm{T}$ helper cell 1-type CD4+ T cells, but not $\mathrm{B}$ cells, mediate colitis in interleukin 10-deficient mice. J Exp Med (1996) 184(1):241-51. doi: 10.1084/ jem.184.1.241

29. Wilson MS, Ramalingam TR, Rivollier A, Shenderov K, Mentink-Kane MM, Madala SK, et al. Colitis and intestinal inflammation in IL10-/- mice results from IL-13Ralpha2-mediated attenuation of IL-13 activity. Gastroenterology (2011) 140(1):254-64. doi: 10.1053/j.gastro.2010.09.047

30. Dubrot J, Duraes FV, Harle G, Schlaeppi A, Brighouse D, Madelon N, et al. Absence of MHC-II expression by lymph node stromal cells results in autoimmunity. Life Sci Alliance (2018) 1(6):e201800164. doi: 10.26508/ lsa.201800164

31. Abe J, Shichino S, Ueha S, Hashimoto S, Tomura M, Inagaki Y, et al. Lymph node stromal cells negatively regulate antigen-specific $\mathrm{CD} 4+\mathrm{T}$ cell responses. J Immunol (2014) 193(4):1636-44. doi: 10.4049/jimmunol.1302946

32. Link A, Vogt TK, Favre S, Britschgi MR, Acha-Orbea H, Hinz B, et al. Fibroblastic reticular cells in lymph nodes regulate the homeostasis of naive $\mathrm{T}$ cells. Nat Immunol (2007) 8(11):1255-65. doi: 10.1038/ni1513

33. Mueller SN, Hosiawa-Meagher KA, Konieczny BT, Sullivan BM, Bachmann MF, Locksley RM, et al. Regulation of homeostatic chemokine expression and cell trafficking during immune responses. Science (2007) 317(5838):670-4. doi: $10.1126 /$ science. 1144830

34. Ben-Baruch A, Xu L, Young PR, Bengali K, Oppenheim JJ, Wang JM. Monocyte chemotactic protein-3 (MCP3) interacts with multiple leukocyte receptors. C-C CKR1, a receptor for macrophage inflammatory protein-1 alpha/Rantes, is also a functional receptor for MCP3. J Biol Chem (1995) 270 (38):22123-8. doi: 10.1074/jbc.270.38.22123

35. Nanki T, Shimaoka T, Hayashida K, Taniguchi K, Yonehara S, Miyasaka N. Pathogenic role of the CXCL16-CXCR6 pathway in rheumatoid arthritis. Arthritis Rheum (2005) 52(10):3004-14. doi: 10.1002/art.21301

36. Diegelmann J, Seiderer J, Niess JH, Haller D, Goke B, Reinecker HC, et al. Expression and regulation of the chemokine CXCL16 in Crohn's disease and models of intestinal inflammation. Inflammation Bowel Dis (2010) 16 (11):1871-81. doi: 10.1002/ibd.21306

37. Finnegan A, Grusby MJ, Kaplan CD, O'Neill SK, Eibel H, Koreny T, et al. IL-4 and IL-12 regulate proteoglycan-induced arthritis through Stat-dependent mechanisms. J Immunol (2002) 169(6):3345-52. doi: 10.4049/jimmunol. 169.6.3345

38. Morita Y, Yang J, Gupta R, Shimizu K, Shelden EA, Endres J, et al. Dendritic cells genetically engineered to express IL-4 inhibit murine collagen-induced arthritis. J Clin Invest (2001) 107(10):1275-84. doi: 10.1172/JCI11490

39. Woods JM, Katschke KJ, Volin MV, Ruth JH, Woodruff DC, Amin MA, et al. IL-4 adenoviral gene therapy reduces inflammation, proinflammatory cytokines, vascularization, and bony destruction in rat adjuvant-induced arthritis. J Immunol (2001) 166(2):1214-22. doi: 10.4049/jimmunol.166.2.1214

40. Specht S, Arriens S, Hoerauf A. Induction of chronic colitis in IL-10 deficient mice requires IL-4. Microbes Infect (2006) 8(3):694-703. doi: 10.1016/ j.micinf.2005.09.006

Conflict of Interest: The authors declare that the research was conducted in the absence of any commercial or financial relationships that could be construed as a potential conflict of interest.

Copyright (ㄷ) 2021 Basic, Peppermüller, Bolsega, Bleich, Bornemann, Bode and Buettner. This is an open-access article distributed under the terms of the Creative Commons Attribution License (CC BY). The use, distribution or reproduction in other forums is permitted, provided the original author(s) and the copyright owner(s) are credited and that the original publication in this journal is cited, in accordance with accepted academic practice. No use, distribution or reproduction is permitted which does not comply with these terms. 